\title{
Sensitive and reliable PCR and sequencing used to detect p53 point mutations in fine needle aspirates of the breast
}

\author{
G P Howes, J Stephenson, S Humphreys
}

\begin{abstract}
Aims/background-Fine needle aspirates (FNAs) of breast lesions are now a routine investigation and prognostic information at this stage would be useful for accurate management. p53 gene status can be used as prognostic indicator, an abnormal genotype being associated with high grade, oestrogen receptor poor tumours. As the main disadvantage with FNA is poor cellularity, the objective of this study was to develop a sensitive and reliable method for the assessment of the p53 status of the lesion.

Methods-Using PCR and subsequent direct sequencing, a method was developed that enables analysis of the p53 gene from relatively few malignant or suspicious cells in a background of normal cells.

Results-This method is both reproducible and sensitive. The sensitivity of the method is demonstrated and a mutant cell can be seen in a background of $90 \%$ of normal wild type cells. A mutation, not previously described in breast cancer, is also reported in a symptomatic FNA.

Conclusions-This methodology is reliable and effective on samples with both variable cell numbers and quality of preservation, allowing it to be applied successfully to diagnostic cytology.

(F Clin Pathol 1996;49:570-573)
\end{abstract}

Keywords: p53, breast cancer, point mutation, fine needle aspiration.

Fine needle aspiration (FNA) is an established preoperative diagnostic procedure. As a sensitive method with high specificity, and because it is minimally invasive, it is readily acceptable to the patient as a diagnostic investigation. Additional advantages of FNA are the speed of processing and the relatively short time in which a report can be generated. The main disadvantage of FNA is the small numbers of cells made available for investigation, which illustrates the requirement for reliable and sensitive analytical methods.

FNAs of the breast are commonly used in both symptomatic patients and those referred for assessment from the National Breast Screening Programme. A diagnosis is made preoperatively and therefore appropriate patient management can be planned. In the case of benign breast disease, surgery may be avoided altogether. ${ }^{12}$
The tumour suppressor gene $\mathrm{p} 53$ is the most

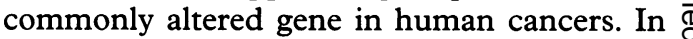
breast cancer, a mutant p53 gene is present in between 20 and $30 \%$ of patients and this has been demonstrated to be of prognostic significance. A mutant p53 gene is also a valuable marker of malignancy and is often used as additional evidence for the presence of malig- 8 nancy. The biological status of p53 can further $\overrightarrow{0}$ be used to determine therapeutic response to either chemotherapy or radiotherapy. ${ }^{3-10}$

The knowledge of the p53 status of the patient at the preoperative stage of their management would enable the cytopathologist to give prognostic, diagnostic and possibly therapeutic information. This information may-for example, lead to decisions involving more radical surgery or adjuvant therapy, or both. ${ }^{11}$

As DNA sequencing is the definitive method for determining the p53 status of the patient, we have developed a reliable and sensitive method involving PCR and direct sequencing to obtain this information from small numbers of cells obtained from FNAs of the breast.

\section{Methods}

CYTOLOGICAL COLLECTION AND PREPARATION Specimens were collected from patients undergoing routine FNA of breast lesions. Aspiration was carried out at the time of imaging and conventional cytological smear preparations made. The needles used were subsequently washed out in RMPI 1640 (Sigma, Poole, Dorset, UK). It was possible to store these $\widetilde{N}$ samples for up to five days at $4^{\circ} \mathrm{C}$ prior to $N$ preparation.

Needle washings were centrifuged in order to determine the size of the cellular deposit. The sample was then rediluted in an appropriate amount of RMPI 1640 prior to cytocentrifugation in order to achieve a monolayer of $\tau$ cells on the surface of a slide. One slide was immediately fixed in absolute alcohol for $\stackrel{\mathbb{Q}}{\square}$ subsequent PAP staining. Other preparations $\stackrel{\mathbb{Q}}{\Omega}$ were air-dried, wrapped in tin foil and stored at 2 $-70^{\circ} \mathrm{C}$.

Cell numbers were estimated, unstained, by conventional light microscopy. Prior staining or fixation in alcohol/methanol was found to affect the quantity of PCR product gained adversely. The cells were then removed from the slide by rehydrating in an appropriate amount of sterile distilled water. Those samples with sparse cellularity (less than 50 cells) were diluted in $50 \mu \mathrm{l}$ sterile distilled water. 
Table 1 Primers used in the sequencing reactions

\begin{tabular}{lll}
\hline Exon & Sequence & Strand \\
\hline 5 & 5'CCCCTGTCGTCTCTCCAGCC3' & Antisense \\
6 & 5'TAACCCCTCCTCCCAG3' & Antisense \\
7 & 5'TCGGTAAGAGGTGGGC3' & Antisense \\
8 & 5'AGGCGCACTGGCCTCATCTT3' & Sense \\
\hline
\end{tabular}

Those samples with greater cellularity were diluted accordingly - that is, those specimens where there was an even coverage of cells across the slides were diluted in $200 \mu \mathrm{l}$ sterile distilled water. Negative controls consisted of sterile distilled water only.

Cell lysis was carried out as described by Kovach $e t \mathrm{al}^{12}$ with the following modifications. Rehydrated samples were diluted with an equal volume of PCR buffer (1X) which also contained $20 \mathrm{mM}$ dithiothreitol, $1.7 \mathrm{mM}$ sodium dodecyl sulphate and $0.1 \mathrm{mg} / \mathrm{ml}$ proteinase $\mathrm{K}$. The digestion was carried out at $55^{\circ} \mathrm{C}$ for 60 minutes with subsequent inactivation at $95^{\circ} \mathrm{C}$ for 10 minutes. The samples were then centrifuged at $15000 \mathrm{rpm}$ for 10 minutes at $4^{\circ} \mathrm{C}$ to remove cell debris

\section{PCR AMPLIFICATION}

The supernatant $(10 \mu \mathrm{l})$ was used as substrate for nested PCR, which was comprised of two rounds using the following primers: first round PCR: 5' GCTCGCTAGTGGGTTGCAGGA 3 and (outer) 5' GCCCAACAACACCAGCTCCTCT 3'; second round PCR: 5' CCGCTTCTTGTCCTGCTTGCT 3' and (inner) 5' TT TCTTTGCTGCCGTGTTCAA 3'.

Nested PCR produces a 1.6 kilobase fragment encompassing exons 5-8. Both sets of primers have identical optimal PCR conditions. The PCR mixture contained $0.5 \mu \mathrm{M}$ of each primer, $20 \mu \mathrm{M}$ of each dNTP, $1 \mathrm{X}$ PCR buffer, and two units of Taq polymerase (Boehringer Mannheim, Lewes, UK), made up to a final volume of $50 \mu \mathrm{l}$. The samples were placed on a Techne GeneE thermocycler (Cambridge, UK) for 30 cycles, comprised of 60 seconds denaturing at $94^{\circ} \mathrm{C}, 60$ seconds annealing at $61^{\circ} \mathrm{C}$, and an extension step at $72^{\circ} \mathrm{C}$ for 150

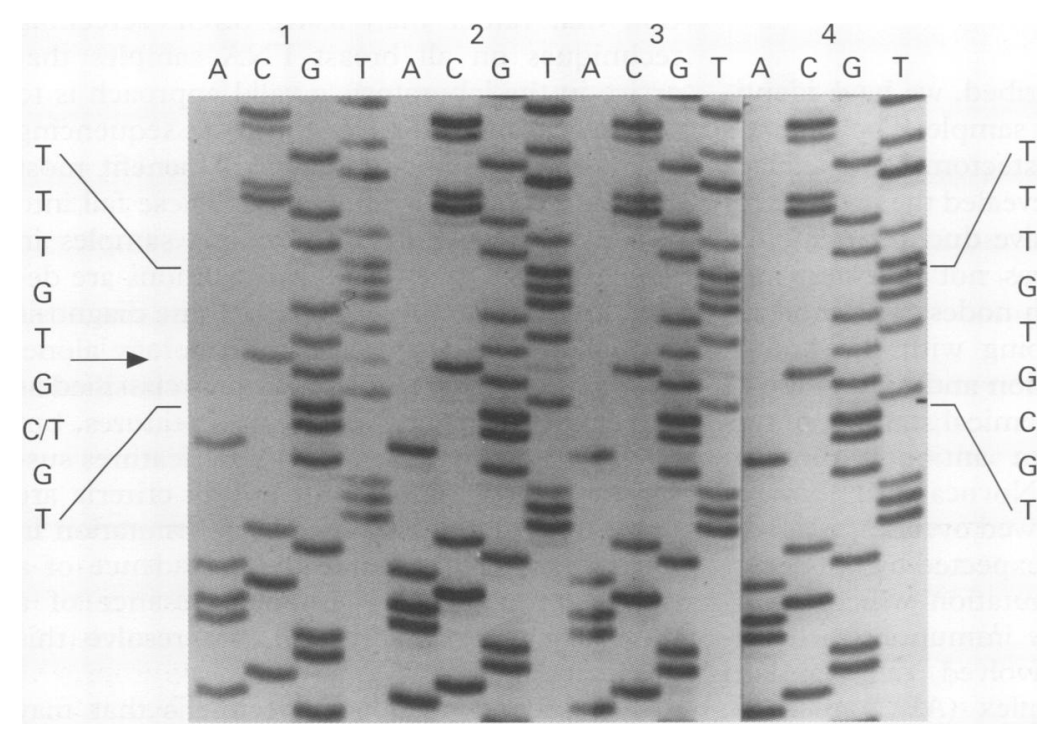

Figure 1 The ratio of mutant alleles to wild type alleles is: sample (1), 25\%; sample (2), 10\%; sample (3), 5\%. Sample (4) illustrates wild type sequence. seconds. A lengthened denaturation and extension step preceded and followed the cycling part of the method; $5 \mu$ l of the product obtained from the first round PCR was used as substrate for the second round PCR.

Two reactions were carried out using a biotinylated form of either the sense or antisense primer to allow separation of the coding or non-coding strand with Streptavidin coated magnetic beads (Dynal UK Ltd, Wirral, UK). Strand separation was carried out as follows. Briefly, $160 \mu \mathrm{l}$ of the second PCR product was purified and precipitated in $8 \mathrm{M}$ ammonium acetate and isopropanol, allowed to dry and resuspended in $80 \mu \mathrm{l} \mathrm{TE}$ buffer $(10 \mathrm{mM}$ Tris$\mathrm{HCl}, 1 \mathrm{mM}$ EDTA, pH 7.5). Then, $80 \mu \mathrm{l}$ Streptavidin coated beads was washed three times in Triton wash solution (TWS) $(0.17 \%$ Triton X-100, $100 \mathrm{mM} \mathrm{NaCl}, 10 \mathrm{mM}$ Tris- $\mathrm{HCl}, \mathrm{pH} 7.5,1 \mathrm{mM}$ EDTA) and resuspended in $80 \mu \mathrm{l}$ TWS. The resuspended PCR product was diluted with a further $80 \mu \mathrm{l}$ TWS prior to the addition of the beads. The mixture was placed on a shaker for 30 minutes. Denaturation of the strands was achieved by taking up the washed beads in $32 \mu \mathrm{TE}$ buffer and $8 \mu \mathrm{l} 1 \mathrm{M} \mathrm{NaOH}$ containing $4 \mathrm{mM}$ EDTA for two incubations of five minutes. The beaded PCR products were washed twice in TWS and taken up in $25 \mu$ l sterile, distilled water and stored at $-20^{\circ} \mathrm{C}$ until sequencing reactions were carried out.

\section{SEQUENCING}

Sequencing was carried out according to manufacturer's instructions for the Sequenase version $2.0 \mathrm{Kit}$ (Amersham International, Little Chalfont, UK). For each sequencing reaction, $7 \mu \mathrm{l}$ of the PCR product/bead complex was annealed with $1 \mu \mathrm{l}$ primer $(1 \mu \mathrm{M})$ and $2 \mu \mathrm{l}$ reaction buffer. Table 1 shows the sequencing primers used. The internal PCR primers were also used successfully as sequencing primers.

\section{PCR SENSITIVITY DETERMINATION}

The sensitivity of the PCR was established using control human tumour cells. These cells were harvested from imprints of tumour tissue in the same manner that FNA cells were prepared. The tumour cells had previously been fully characterised as diploid cells that possessed one wild type allele and one mutant allele. The mutation in these cells was a CGT to TGT base substitution at codon 273 (in exon 8 ). The mutation was seen, as expected, in association with a normal allele. Variable dilutions of the tumour cells against fully wild type cells (from normal tissue) was carried out to establish PCR sensitivity. The sequencing showed the presence of the mutation in all tracks.

Figure 1 demonstrates the unequivocal detection of the mutation when the genotypically altered cells are at a concentration of $10 \%$ in a background of normal cells. This therefore illustrates the mutant sequence in a background of $95 \%$ wild type sequence. A wild type sequence is also adjacent to these mutant 


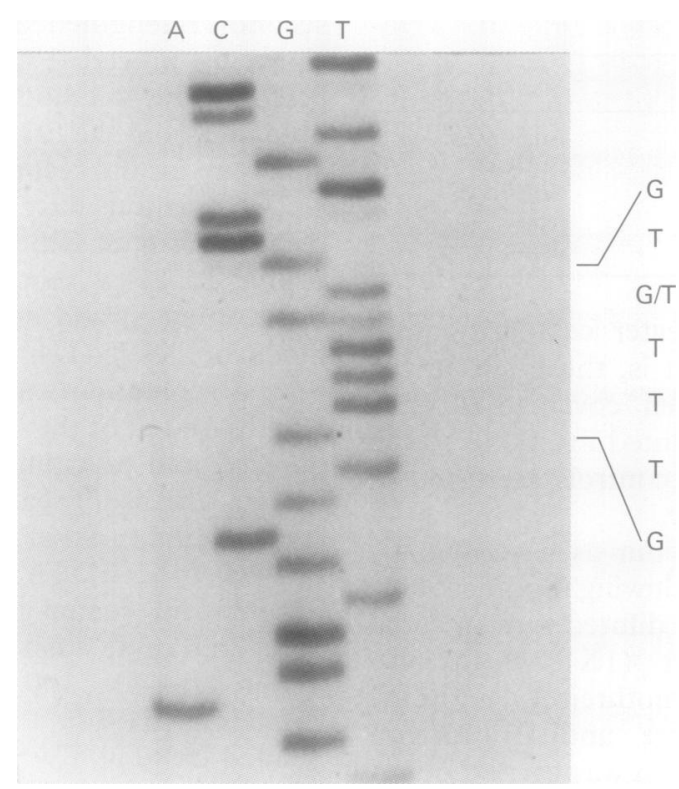

Figure 2 Mutation at codon 275 (TGT to TTT) on the sense strand in the presence of the normal allele.

sequences in order to demonstrate and confirm the sensitivity and specificity of the PCR.

\section{Results}

The sensitivity experiments have demonstrated that one mutant allele can be detected in a background of $95 \%$ fully wild type alleles. This illustrates both the sensitivity and the extreme specificity that is characteristic of nested PCR.

Figure 2 shows the application of the methodology to cells obtained from a breast lesion in a symptomatic patient. The patient, aged 58 years at diagnosis, presented with a clinically and radiologically malignant mass. This mass was aspirated in clinic in order to obtain proof of the nature of the lesion, which was subsequently confirmed as malignant by cytology. The use of the PCR/sequencing methods described here demonstrated the presence of a mutation in the p53 gene. This mutation was detected at codon 275 (in exon 8 ) and is a known oncogenic change (a TGT to TTT substitution mutation with an amino acid change of Cys to Phe) (fig 2).

\section{Discussion}

Using the methods described, we have identified a mutation in a FNA sample. The patient's subsequent surgery (mastectomy and axillary lymph node clearance) revealed the presence of a $6 \mathrm{~mm}$, grade III, invasive ductal carcinoma. Metastatic carcinoma was not detected in a total of 14 axillary lymph nodes. The molecular findings are in keeping with the known association of $\mathrm{p} 53$ mutation and high grade of tumour. Immunohistochemical staining of this excised tumour with an antibody directed against p53 (PAb 1801; Novocastra Laboratories, Newcastle, UK) showed overexpression of the protein, as would be expected by the detection of an oncogenic mutation which would stabilise the protein. The immunohistochemical method used involved a standard Streptavidin-biotin complex (ABC) method, with 30 minutes pretreatment in citrate buffer (pH 6.0) in a microwave oven.
Use of the Cariello p53 mutation database ${ }^{13}$ draws attention to the significance of the mutation reported here. The mutation has been documented previously in a non-small cell lung carcinoma, ${ }^{14}$ a $\mathrm{B}$ cell lymphoma ${ }^{15}$ and $\mathrm{a}$ colorectal carcinoma, ${ }^{16}$ but not in breast $\bigcirc$ cancer. Other changes at this codon (a Trp and $\overline{5}$ an Arg substitution) have been described in breast cancer. ${ }^{17} 18$

PCR-SSCP is an alternative method used in 을 many laboratories for the determination of $\mathrm{p} 53 \overrightarrow{\mathrm{F}}$ status. Preliminary work in this laboratory used additional PCR primers to generate fragments of 100-200 base pairs and compared SSCP results with sequencing results on samples $\mathbb{\Omega}$ derived from colon and liver tumours. This showed that the PCR/direct sequencings methodology described here has many advan-? tages and SSCP was not therefore attempted $\overrightarrow{\vec{\omega}}$ on FNA samples.

The methods described are more sensitive $\frac{\bar{\gamma}}{\delta}$ SSCP requires more of the sample to containi the mutation before a band with altered migra tion would be detected. Our methods are morev reproducible; SSCP is highly dependant on small changes in electrophoresis conditions, $\stackrel{\circ}{-}$ permitting detection of each mutation. There $\vec{c}$ are some mutations which will not produce bands of altered mobility and will never bedetectable by SSCP. These techniques arec unequivocal; the presence of a band with? altered migration on an SSCP gel cannot beo assumed to be a mutation rather than a neutral polymorphism or even a gel artefact unless it iso sequenced or unless that particular mutation is run on the same gel as a control. Finally, the methods described here give more information $\overrightarrow{\vec{B}}$ than SSCP, allowing individual mutations to be correlated with outcome.

SSCP may have advantages when a very large number of samples need to be screened (most particularly when this is for one specifico mutation of known significance) prior to sequencing, but cannot be recommended as aᄋ̊ technique to be used alone to provide results for use in establishing prognosis, being prone을 to false positives and not capable of universal detection of mutations. We have taken the position that rather than using SSCP screening techniques on all breast FNA samples that arrive in the laboratory, a valid approach is ton select samples for PCR/direct sequencing ${ }_{0}^{\omega}$ analysis from patients who will benefit mosto from knowing their p53 status. These fall into two categories: the first contains samples in $\stackrel{\infty}{?}$ which further diagnostic investigations are de- 0 sirable-for example, when a definite diagnosis cannot be reached on the morphology alone. $\stackrel{\mathbb{Q}}{\mathbb{Q}}$ This group includes those samples classified as $\stackrel{\mathbb{Q}}{\mathbb{Q}}$ C3 (some suspicious or atypical features, buto likely to be benign) and C4 (have features sus- $\varnothing$ picious of malignancy, but not all criteria areo met). The identification of a p53 mutation in these cases will enhance the confidence of a malignant diagnosis (although absence of a molecular abnormality will not resolve this predicament).

The second group of specimens that may benefit from molecular studies are those that require additional prognostic information. 
FNA samples from patients who are being considered for neoadjuvant chemotherapy would fall into this group. Indeed, when studying p53 status in order to predict therapeutic response, molecular methods such as the PCR/ direct sequencing described here are the methods of choice, so that any p53 mutations may be characterised fully. Null p53 status (due to frame shift or nonsense mutations) - for example, will lead to increased sensitivity to chemotherapeutic agents, whereas mutant p53 that has a gain of function mutation (mainly base substitution mutations) will have increased resistance to chemotherapy. Those patients with wild type p53 on both alleles can be predicted to respond to therapy, due to the involvement of p53 in triggering apoptosis. ${ }^{19}$ Precise data, such as these, cannot be determined by immunohistochemistry or PCRSSCP alone. However, further work is required to fully evaluate the role of p53 in the chemotherapeutic response, as consistent data are seen rarely. ${ }^{20} 21$

The main advantage of the methods reported is its extreme sensitivity in the presence of excess wild type sequences, and its reliability. There is a only a single variable in the method between samples, and that is the volume of diluent used to rehydrate the cells prior to proteinase $\mathrm{K}$ digestion. The method can also be completed within three to four days.

In summary, the methodology reported here is reliable and effective on samples with both variable cell numbers and quality of preservation, allowing it to be applied successfully to diagnostic cytology.

This work was funded by the British Society for Clinical Cytology.

1 Dowell SP, Wilson POG, Derias NW, Lane DP, Hall PA Clinical utility of the immunocytochemical detection of p53 protein in cytological specimens. Cancer Res 1994 54:2914-8.

2 Wells CA, Ellis IO, Zakhour HD, Wilson AR. Guidelines for cytology procedures and reporting on fine needle aspirates of the breast. Cytopathology 1994;5:316-34.

3 Stephenson TJ, Royds JA, Silcocks PB, Brammer HJ, Shorthouse AJ, Underwood JCE. Diagnostic associations of $\mathrm{p} 53$ immunostaining in fine needle aspiration cytology of the breast. Cytopathology 1994;5:146-53.

4 Bártek J, Bártková J, Vojtesek B, Stasková Z, Rejthar A, Kovarik J, et al. Patterns of expression of the p53 tumour suppressor in human breast tissues and its tumours in situ and in vitro. Int $\mathcal{F}$ Cancer 1990;46:839-44.

5 Levine AJ, Chang A, Dittmer D, Notterman DA, Silver A, Thorn K, et al. The p53 tumour suppressor gene. f Lab Clin Med 1994;123:817-23.

6 Tsuda $\mathrm{H}$, Iwaya K, Fukutomi T, Hirohashi S. P53 mutations and c-erbB-2 amplification in intraductal and invasive breast carcinomas of high histologic grade. $f p n \mathcal{F}$ Cancer Res 1993;84:394-401.

7 Barnes DM, Dublin EA, Fisher CJ, Levison DA, Millis RR. Immunohistochemical detection of $\mathrm{p} 53$ protein in mammary carcinoma: an important new independent indicator of prognosis. Hum Pathol 1993;24:469-76.

8 Bozzetti C, Nizzoli R, Naldi N, Manotti L, Savoldi L, Camisa R, et al. Fine-needle aspiration technique for the concurrent immunocytochemical evaluation of multiple biologic parameters in primary breast carcinoma. Breast biologic parameters in primary
Cancer Res Treat 1994;32:221-8.

9 Wood WC. Integration of risk factors to allow patient selection for adjuvant systemic therapy in lymph node-negative breast cancer patients. World f Surg 1994;18:39-44.

10 Elledge RM, Allred DC. The p53 tumor suppressor gene in breast cancer. Breast Cancer Res Treat 1994;32:39-47.

11 Ljung B, Chew K, Deng G, Matsumura K, Waldman F, $\mathrm{Smith} \mathrm{H}$. Fine needle aspiration techniques for the characSmith H. Fine needle aspiration techniques for the char

12 Kovach JS, McGovern RM, Cassady JD, Swanson SK, Wold LE, Vogelstein B, et al. Direct sequencing from touch preparations of human carcinomas: analysis of p 53 mutations in breast carcinomas. F Natl Cancer Inst 1991; 83:1004-9.

13 Cariello NF, Cui L, Beroud C, Soussi T. Database and software for the analysis of mutations in the human p 53 gene. Cancer Res 1994;54:4454-60.

14 Suzuki H, Takahashi T, Kuroishi T, Suyama M, Ariyoshi Y, Ueda R. p53 mutations in non-small-cell lung cancer in Japan: association between mutations and smoking. Cancer Res 1992;52:734-6.

15 Sander CA, Yano T, Clark HM, Harris C, Longo DL, Jaffe $\mathrm{ES}$, et al. p53 mutation is associated with progression in follicular lymphomas. Blood 1993;82:1994-2004.

16 De-Angelis P, Stokke T, Smedshammer L, Lothe RA, Meling GI, Rofstad MYC. P53 expression is associated with a high degree of tumor DNA aneuploidy and incidence of 53 gene mutation, and is localized to the anciploid compartment in colorectal carcinomas. Int $f$ Oncol 1993;3:305-12.

17 Sommer SS, Cunningham J, McGovern RM, Saitoh S, Schroeder JJ, Wold LE, et al. Pattern of p53 gene mutations in breast cancers of women of the Midwestern United States. I Natl Cancer Inst 1992;84:246-52.

18 Davidoff AM, Iglehart JD, Marks JR. Immune response to p53 is dependent upon p53/hsp70 complexes in breast cancers. Proc Natl Acad Sci USA 1992;89:3439-42.

19 Lowe SW, Ruley HE, Jacks T, Housman DE. P53dependent apoptosis modulates the cytotoxicity of anticancer agents. Cell 1993;74:957-67.

20 Makris A, Powles TJ, Dowsett M, Allred C. p53 protein overexpression and chemosensitivity in breast cancer. Lancet 1995;345:1181-2.

21 Petty RD, Cree IA, Sutherland LA, Hunter EM, Lane DP, Preece PE, et al. Expression of the p53 tumour suppressor gene product is a determinant of chemosensitivity. Biochem Biophys Res Commun 1994;199:264-70. 